\title{
USING A GPS TRACKER IN OPERATING AND MANAGING FARM MACHINERY STATIONS
}

\section{H. H. Mohamed}

\section{ABSTRACT}

GPS tracking system is a great tool for operating and managing farm machinery stations, which allows tracking all farm machinery as they operate in the field, giving the ability to contact machine driver in the field and see if anybody is going over the areas already worked. A Lamborghini (R 3) $95 \mathrm{hp}$ tractor and a chisel plow were tested with GPS tracking system to measure the effect of using GPS tracking system on the performance of farm machinery. Using GPS tracking system with Google Maps provides important information about field shape, area, dimensions and position of the machine on the map which leads to increase the performance of the machine in the field. GPS tracking system prevents drifting, keep farm machinery on track, avoids the gaps and overlaps that affect the quality of the work.

An advancement plan was designed to increase the performance of governmental farm machinery stations, which includes use GPS tracker, use renewable energy, organize training courses to drivers, create a database for all farm machinery in the station, make time plan to replace old machines, improve the management system for the farm machinery station and finally use computer program for technical service support.

Keywords :, GPS tracker, Chisel plow, Google Maps, Maintenance program, Farm machinery station.

\section{INTRODUCTION}

7 he agricultural mechanization program in Egypt at 1990 was allocated for full mechanization of the main crops as cotton,

grains and fodders. The program succeeded to provide extension, custom services and funds to purchase several types of machines. It also succeeded in establishing many farm machinery stations and maintenance centers to provide machinery and equipment to farmers (including repairs and maintenance).

\footnotetext{
*Lecturer, Soil \& Ag. Eng. Dept., Fac of Agric. Saba Basha, Alexandria University, Egypt.
} 
The number of farm machinery stations in Egypt is about 160 station distributed all over Egypt. The farm machinery stations rent tractors, cultivators, planters, fertilizers, mowers and harvesters to farmers with low prices (CAPMAS, 2014).

Kutz (2013) reported that farm machinery use GPS to determine position, speed and to steer the vehicle in the proper direction. The GPS system use signals emitted from 24 satellites orbiting the Earth to determine the geographic position of the receiver. The satellites emit signals in two frequency bands to improve the accuracy of the position signals. The nominal accuracy of GPS systems is $10-20 \mathrm{~m}$ with single-band receivers and 5-10 $\mathrm{m}$ with dual-band receivers.

Ehsani (2013) reported that machine production in the field is affected by the following factors: driver skill, machine lifetime and field conditions such as (size, shape, topography, row length and row end turning space) which affect on how driver can drive in the field.

Calculating field efficiency was difficult in the past because it required someone with a stopwatch during operation to calculate time consumption. Now, GPS can be used to obtain this information much faster and easier. GPS receivers send out strings of data that contain information about the position (latitude, longitude and elevation), speed and time.

Shamshiri and Ishak (2013) reported that global positioning system (GPS) enabled navigation technologies such as automated guidance systems (AG) which have been commercially available for several years. The global positioning system benefits include: 1) Reduction in overlap, 2) Increase operation speed, and 3) Decrease actual time consumption. GPS are an example of an embodied knowledge technology that increases efficiency without requiring additional management skills.

Dahab and Mohamed (2006) defined farm mechanization as the use of machines for production processes. Crop production involves a sequence of actions, operations and other factors that affect production. A good farm management plan has to analyze the whole farming system for maximizing production and minimizing risks. The farm manager has to 
study the relationships between machines, weather and crop combinations. Management can more or less control machine capacity (machine width, speed, and field efficiency), as well as selection of implements, operations and crops. Computer systems can facilitate the examination of these relationships. This research was carried out to:

1) Linking farm machinery with operating station electronically by GPS tracking system.

2) Decrease labor hours, fuel consumption, lubrication and spare parts cost for farm machinery.

3) Increase field efficiency of farm machinery.

4) Improve governmental farm machinery stations.

\section{MATERIALS AND METHODS}

The research was done at the Station of Tractors and Agricultural Machinery in Alexandria. A GPS tracking system was used in operating Lamborghini (R3) $95 \mathrm{hp}$ tractor to conduct tillage process using a chisel plow at the Faculty of Agriculture (Saba Basha) experimental farm. The technical specifications of the tractor and chisel plow are shown in Tables (1) and (2) respectively:

Table (1): Tractor technical specifications.

Table (2).Chisel plow specifications.

\begin{tabular}{|c|c|c|c|}
\hline Engine LAMBORGHINI & 1000.4 WT EUR0 II & Model & Brillion 2-Bar Mounted \\
\hline$\frac{\text { Cylinders/Displacement, } \mathbf{n o} / \mathrm{cm}^{3}}{\text { Aspiration }}$ & $\frac{4 / 4000}{\text { Turbo }}$ & Approximate Weight & $328 \mathrm{~kg}$ \\
\hline Max. homologated power, $\mathrm{HP} / \mathrm{kW}$ & $96 / 70.5$ & Working Width & $2.1 \mathrm{~m}$ \\
\hline Nominal engine speed, rpm & 2300 & Overall Length & $1.6 \mathrm{~m}$ \\
\hline $\begin{array}{c}\text { Max. torque, } \mathrm{Nm} \\
\text { Max. torque engine speed rpm }\end{array}$ & $\frac{367}{1400-1600}$ & Number of Shanks & 7 \\
\hline Fuel tank capacity, liter & 160 & Shank Size and type & $(25.4 \times 76.2 \times 660 \mathrm{~mm})(3$ inch shovel $)$ \\
\hline Min. speed, km/h & 0.34 & Shank Spacing & $300 \mathrm{~mm}$ \\
\hline $\begin{array}{l}\text { Max. speed, } \mathrm{km} / \mathrm{h} \\
\text { Steering angle 4WD }\end{array}$ & 40 & Under Frame Clearance & $688 \mathrm{~mm}$ \\
\hline Max. length, mm & 3840 & Frame Structure & $(100 \times 100 \times 4.67 \mathrm{~mm})$ \\
\hline Width min.- max., mm & $\frac{2070-2570}{2720}$ & Working Depth & $150 \mathrm{~mm}$ \\
\hline $\begin{array}{c}\text { Max. height at safety frame, mm } \\
\text { Ground clearance, } \mathrm{mm}\end{array}$ & $\begin{array}{c}2720 \\
475\end{array}$ & Horsepower Requirements & 10 to 15 HP per Shank \\
\hline Minimum steering radius, mm & 4630 & Operating Speed & 6.43 to $9.65 \mathrm{~km} / \mathrm{h}$ \\
\hline
\end{tabular}

\section{GPS tracking system}

Real Time GPS Tracker (RTGT) is a real live tracking system for any farm machine which provides farm operating guidance by managing information by linking it to farms using GIS technology. Every machine should be equipped with GPS signal receiver to operate agricultural 
machines at farm. The system determines machine location in the farm, speed, elevation and records tracks on Google Maps or Open Street Maps. The GPS Tracker system consists of a GPS signal receiver equipped with GPS Tracker program and a PC computer connected with the internet to receive the data and the maps at the station as shown in Fig.(1). The GPS receives position data automatically every two seconds. The accuracy of the GPS signal is affected by atmospheric conditions, obstructions, reflections and the visibility of satellites

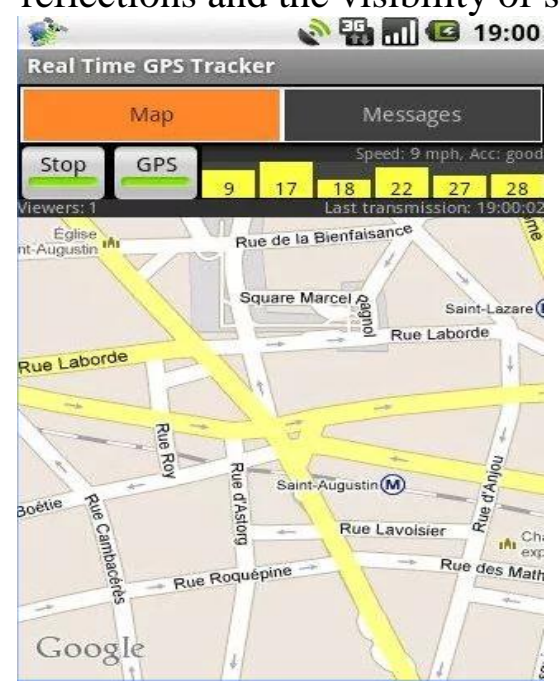

Fig. (1). Real-Time GPS Tracker desktop.

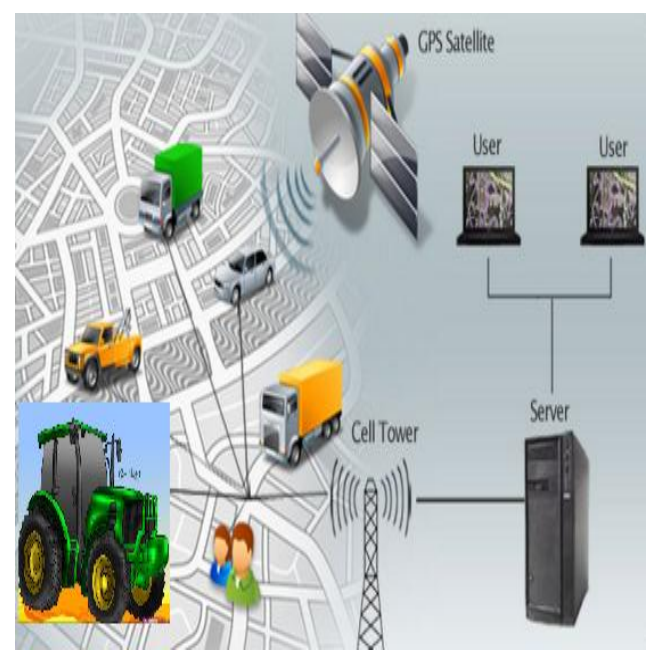

Fig. (2). Diagram of determining location

When the receiver has a clear view of the horizon and can see many satellites, the quality of the position is good and the receiver can accurately determine its position. However, if the weather is bad and there are obstructions that block the signal or cause reflections, such as trees and buildings, the position signal becomes low. Similarly, if there are few satellites in view, or if they are low on the horizon, the position signal also becomes low and has larger error. The GPS receiver sends position data and track to the main server by internet. The server send these data to the pc computer in the station as shown in Fig.(2). There are some techniques that can be used to minimize some of the errors in the positioning signal. Differential GPS (DGPS) receivers use an existing GPS receiver at a known static location on the ground, which is called a 
base station, to correct errors in the position of the mobile receiver as shown in Fig.(3). The difference between the actual location of the static receiver and the measured location of the static receiver (the error) is calculated and broadcast on a radio to the mobile GPS receiver. The mobile receiver then subtracts the error from the measured location of the mobile receiver, correcting for errors caused by the visibility of the satellites and the atmospheric conditions. As the distance from the base station increases, the accuracy of the differential correction decreases.

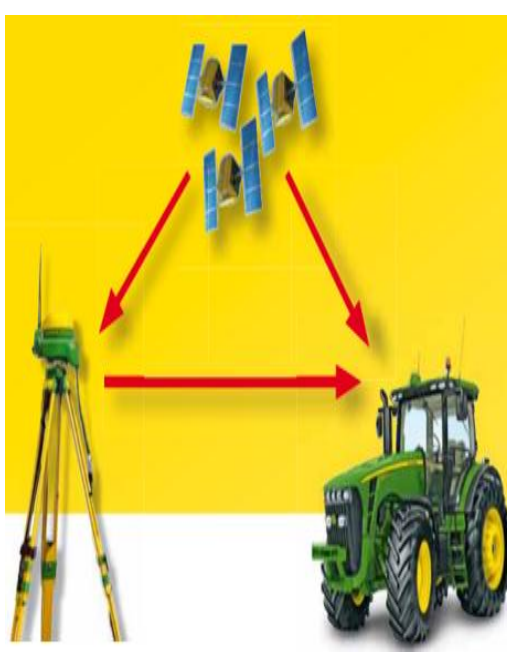

Fig. (3). Differential GPS (DGPS) receivers.

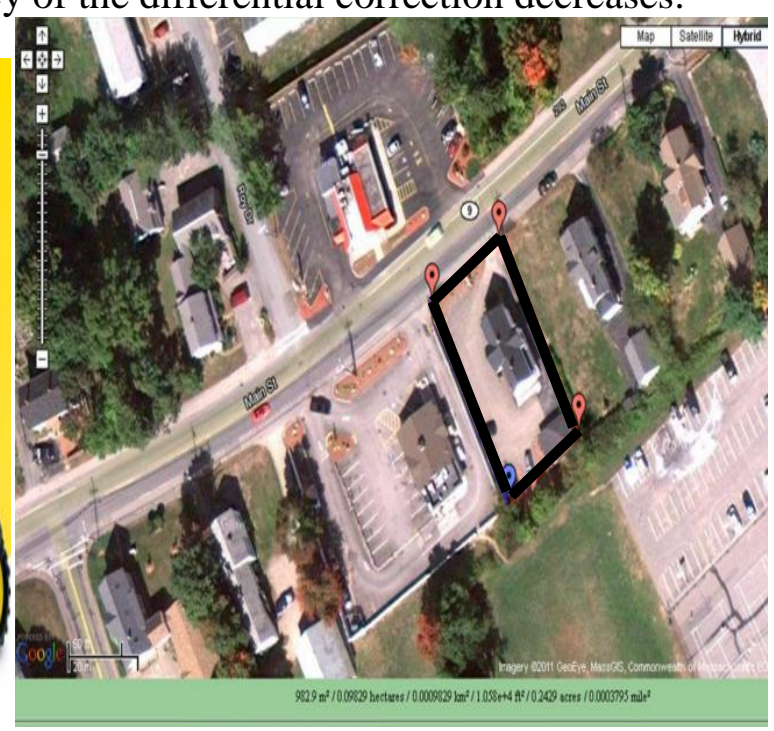

Fig.(4). ACME Planimeter map view.

\section{Measurements}

\section{1- Traveling speed and distance}

The GPS tracking system was used to record traveling speed and distance on the map while working in the field so we can calculate min, max and average speed in the field.

\section{2- Movement direction}

Movement direction is an important factor that affects the actual time consumption. The tracking system tracks the direction of the machine in the field to determine the best direction in the field. Operating farm 
machinery in wrong directions leads to increase time losses and actual time consumption

\section{3- Field area}

ACME Planimeter was used on Google Maps to determine the area that was completed by the machine. ACME Planimeter allows plotting points on the map using Google Maps to give the measurement area as shown in Fig. (4).

\section{4-Theoretical field capacity (TFC)}

The theoretical field capacity of an implement is the rate of field coverage that would be obtained if the machine were performing its function $100 \%$ of the time at the rated forward speed and covered $100 \%$ of its rated width. It can be calculated without using GPS by the following equation:

$\mathrm{TFC},($ feddan $/ \mathrm{h})=\frac{\text { machine width }(\mathrm{m}) \times \mathrm{speed}\left(\frac{\mathrm{km}}{\mathrm{h}}\right)}{4.2}$

\section{5- Actual time consumption (ATC)}

The actual time consumption is the consumed time in (h/feddan) after adding lost time of the machine in the field. The tracking system records the time and the position of the machine every 2 seconds, so we can calculate the actual time consumption and lost time from the map.

\section{6- Actual field capacity (AFC)}

The actual field capacity is the actual field area that can be obtained in one hour, (feddan/h) which can be calculated using the following equation:

$$
\mathrm{AFC}(\text { feddan } / \mathrm{h})=\frac{1}{\text { Actual time consumption }(\mathrm{h} / \text { feddan })}
$$

\section{7- Machine field efficiency (FE).}

The machine field efficiency is the ratio between actual field capacity (AFC) and theoretical field capacity TFC.

\section{8- Estimating tractor size}

It is very important to calculate power requirements for any field operation to determine suitable tractor size for farm needs to decrease both of fuel consumption and operating costs.

\section{A- Determine Engine power and energy consumption}

The engine power and energy consumption were determined using the following equations: 


$$
\text { Engine power }=\frac{\text { PTO power }}{0.85} \quad,(\text { Michelin, 2001) } .
$$

Energy consumption, $\mathrm{kW} \cdot \mathrm{h}=$ Engine power, $\mathrm{kW} \times$ Time consumption, $\mathrm{h}$ The power take off (PTO) can calculated using a multiplying factor, which takes into account the type of soil condition. The multiplying factors are 1.5, 1.8 and 2.1 for untilled soil, tilled soil and sandy soil respectively, as given by (Williams, 2007). In this study:

PTO horsepower $=$ Draw bar power, $\mathrm{kW} \times 1.5$,

The power required at the drawbar from the machine was obtained by using the following equation:

$$
\begin{aligned}
\mathrm{Db} & =\frac{\mathrm{Sr} \times S}{3600} \\
\mathrm{Sr} & =\mathrm{W} \times \mathrm{Wd} \times \mathrm{R}
\end{aligned}
$$

\section{Where:}

Db: Draw bar power, $\mathrm{kW}$

Sr: Soil resistance, $\mathrm{N}$ W: Width, $\mathrm{m}$

$\mathrm{S}:$ Speed, $\mathrm{km} / \mathrm{h}$ Wd: Working depth, $\mathrm{cm}$ R: Resistance coefficient, $\frac{N}{\text { width }(\mathrm{m}) \times \text { depth }(\mathrm{cm})}$

The resistance coefficient $(\mathrm{R})$ was determined according to draft and power requirements table for tillage and seeding machines (Williams, 2007).

\section{6 - Estimating Fuel consumption}

The average fuel consumption is the fuel volume in liter, which the tractor consumes in one hour. It can be calculated in gallon using a multiplying factor of 0.044 for diesel engine using the following equation:

$$
\text { Afc }=\text { PTO } \times 3.78 \times 0.044 \quad,(\text { Michelin, 2001) } \text {. }
$$

Where:

Afc: Average diesel fuel consumption, $1 / \mathrm{h}$

PTO: Power take off, hp

3.78: Factor to transfer gallon to liter

\section{7 - Estimating labor hours}

The actual labor hours usually higher than machine field hours by about 10 to 20 percent, because of travel and the time required to lubricate and maintenance.

\section{RESULTS AND DISCUSSION}

A Lamborghini (R 3) $95 \mathrm{hp}$ tractor and a chisel plow were tested with GPS tracking system in the Faculty of Agriculture (Saba Basha) experimental farm to measure the effect of using GPS tracking system on 
the performance of farm machinery. The specifications of the selected two plots in the farm are shown in Fig. (5). The test was run two times at the same conditions at the selected two plots. The driver was guided by GPS at the first time, while at the second time the driver was not guided by GPS.

\section{The effect of using GPS tracking system on the performance of farm} machinery.

\section{1- Field specifications}

Using GPS tracking system with Google Maps provides important information about field shape, area, dimensions and position of the machine on the map which leads to improve the performance of the machine in the field compared to the current traditional situation where there is no as accurate information about the field as that collected by the GPS so that the performance of the machine in the field is not well controlled and low. The shape of the field is important to determine the prober travel direction in the field. Using wrong directions lead to increasing waste time specially at turning areas at the field heads. The driver should operate agriculture machinery in parallel lines without any deflection from the line drift. GPS tracking system prevents drifting, keep farm machinery on the right track, avoids the gaps and overlaps that affect the quality of the work as illustrated in Fig (6).
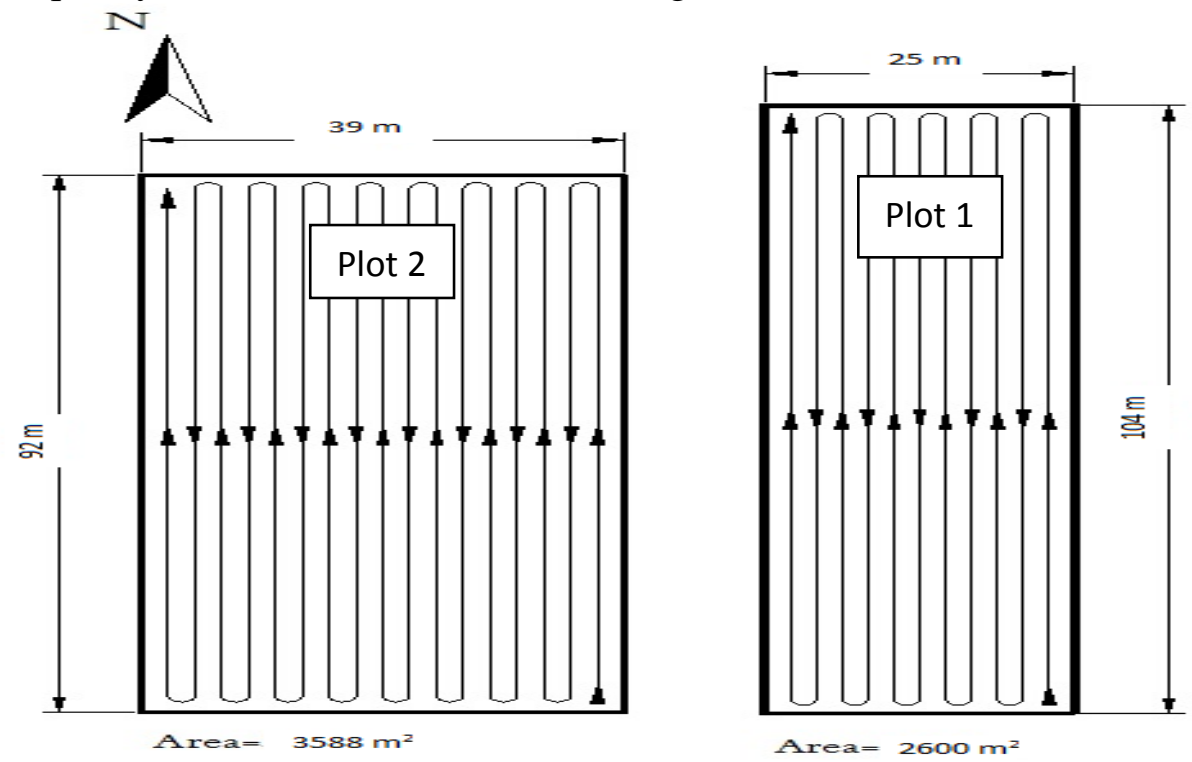

Fig.(5). The track of the tractor in the field with guiding by GPS. 


\section{2- Traveled speed and distance}

At the current man-controlled situation there is no accurate information about the traveled distance and speed but this can be calculated manually by measuring field dimensions and elapsed time in the field, which is too difficult and takes long time. The GPS tracking system records speed, distance and track of the machine on the map automatically.

The min, max and average speeds as recorded by GPS were 2.3, 7 and 5.5 $\mathrm{km} / \mathrm{h}$ respectively. The measured distances by GPS were $1385.5,1987.5$ and 3373 meter for the first plot, the second plot and the whole area respectively, while the measured distances by manual methods were 1851.5, 2545 and $4396.5 \mathrm{~m}$ when the driver was not guided by GPS for the first plot, the second plot and the whole area respectively. Using GPS tracking system in operating farm machinery resulted in decreasing traveled distance by about $25.16,21.9$ and $23.27 \%$ for the first plot, the second plot and the whole area respectively, which is due to machine drifting and overlaps that affect on the quality of the work.

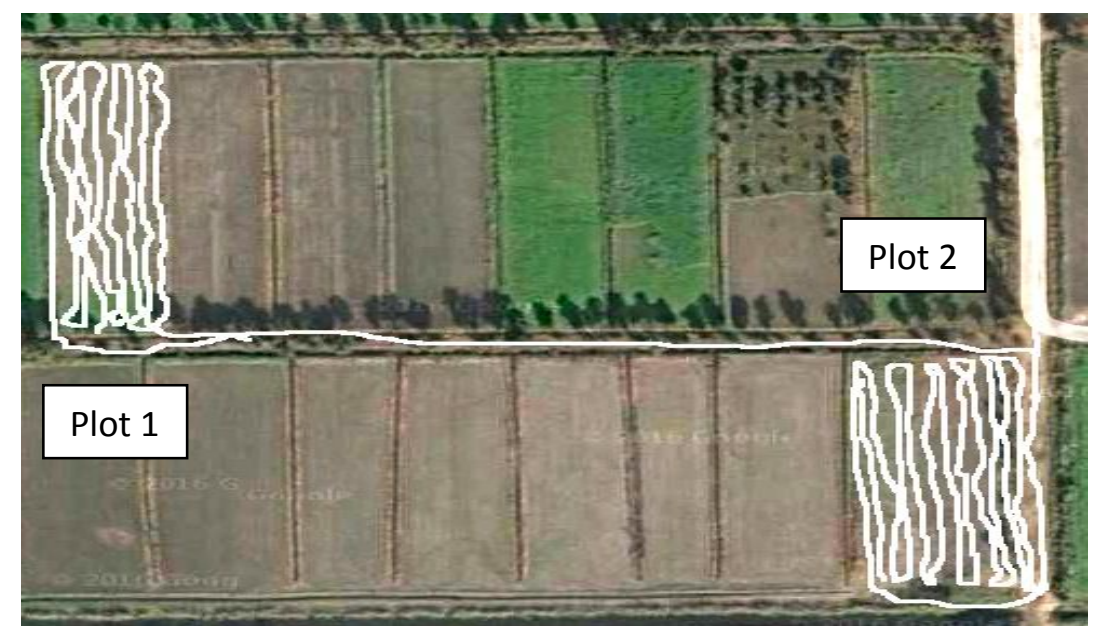

Fig.(6). The track of the tractor in the field without guiding by GPS.

\section{3- Time consumption}

The GPS tracking system records the time every two seconds on the map so the actual time consumption and the waste time can be calculated in the field, while in the current situation the actual time consumption was recorded by a stopwatch. The recorded time consumptions were 20.17, 28.59 and 48.77 minute by using GPS while were $21.84,30.68$ and 52.52 minute by using stopwatch for the first plot, the second plot and the whole 
area respectively. It was observed that using GPS in machine guiding resulted in decreasing waste time by about $17.83,15.5$ and $16.64 \%$ for the first plot, the second plot and the whole area respectively. The GPS tracking system was used to guide the driver and prevent machine drifting and overlaps in the field which lead to decrease actual time consumption by about $7.63,6.79$ and $7.14 \%$ for the first plot, the second plot and the whole area respectively.

\section{4 - Field capacity}

The actual field capacities for the first plot and the second plot were 1.7 and 1.67 (feddan/h) without using GPS, while were 1.84 and 1.79 (feddan/h) when using GPS respectively. Using GPS tracker for tillage process increases the actual field capacity by about 7.63 and $6.79 \%$ for the first plot and the second plot respectively this is due to decrease actual time consumption by using GPS tracker.

\section{5 - Field efficiency}

The field efficiency for the first plot, the second plot and the whole area were $57.21,56.20$ and $56.70 \%$ respectively without using GPS, while were $61.93,60.29$ and $61.11 \%$ respectively with using GPS. Using GPS tracker for tillage process increases the field efficiency by about 7.63, 6.79 and 7.21 for the first plot, the second plot and the whole area respectively this is due to increase the actual field capacity.

\section{6- Energy consumption}

It is very important to calculate energy consumption for any machine before use to determine the suitable tractor power. Using wrong tractor power leads to increase fuel consumption, costs and carbon dioxide which pollute environment. The suitable engine power was $95 \mathrm{hp}$ for the above mention chisel plow specifications at width, speed and depth of $2.27 \mathrm{~m}$ and $5.5 \mathrm{~km} / \mathrm{h}$ and 15 $\mathrm{cm}$ respectively in clay soil. The energy consumptions for the first plot, the second plot and the whole area were $26.62,37.74$ and $64.36 \mathrm{~kW} / \mathrm{h}$ with using GPS, while were 28.82, 40.49 and $69.31 \mathrm{~kW} / \mathrm{h}$ without using GPS respectively. Using GPS tracker at tillage process decreases the energy consumption by about 7.63, 6.79 and $7.14 \%$ for the first plot, the second plot and the whole area respectively this due to decrease the actual time consumption.

\section{7 - Fuel consumption}

Fuel consumption is very important factor to evaluate the performance of the tractor and calculate operating cost. The fuel consumptions for the first plot, 
the second plot and the whole area were 5.12, 7.25 and 12.37 liter with using GPS tracker, while were 5.54, 7.78 and 13.33 liter without using GPS respectively. Using GPS tracker for tillage operation decreases fuel consumptions by about 7.63, 6.79 and $7.13 \%$ for the first plot, the second plot and the whole area respectively this is due to decrease the actual time consumption.

\section{8 - Labor hours}

The farm machinery station is renting tractors and machines to farmers per hour. The cost of renting $95 \mathrm{hp}$ tractor with chisel plow was about 60 LE per hour. The station employee estimates labor hours after complete work in the field to determine labor cost. The total labor hours was $0.93 \mathrm{~h}$ with using GPS, while was one hour without using GPS for the total area of 1.47 feddan; this due the effect of machine drifting and overlaps in the field which lead to increase labor hours by about $7.14 \%$.
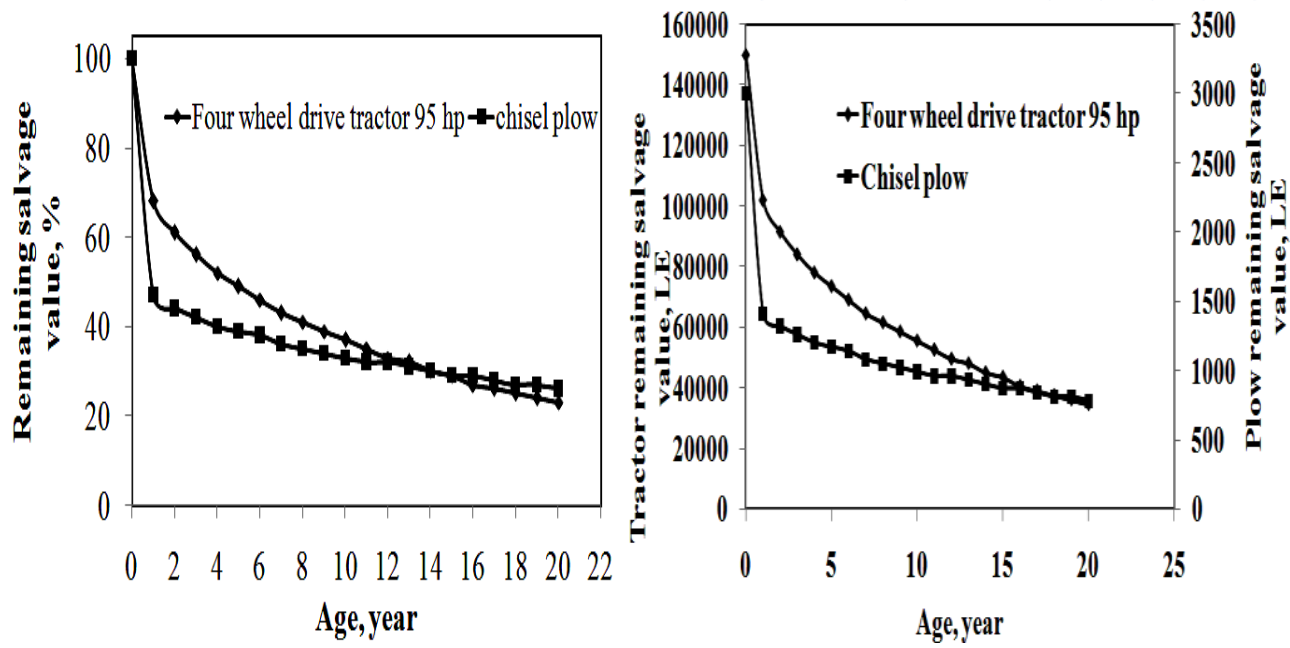

Fig. (7). The relationship between remaining salvage value and machine age.

\section{9- Farm machinery salvage value}

The salvage value for any machine is the current value of the machine that have already been owned for several years which depends on original purchase price and machine age. The relationship between salvage value and age for the above mentioned tractor and chisel plow are shown in Fig. (7), according to ASAE (2000) it was observed that increasing machine age resulted in decreasing salvage value from 100 to $20 \%$ through 20 year. It is very important to calculate salvage value every year for all machines at the farm machinery station to replace old machines. 

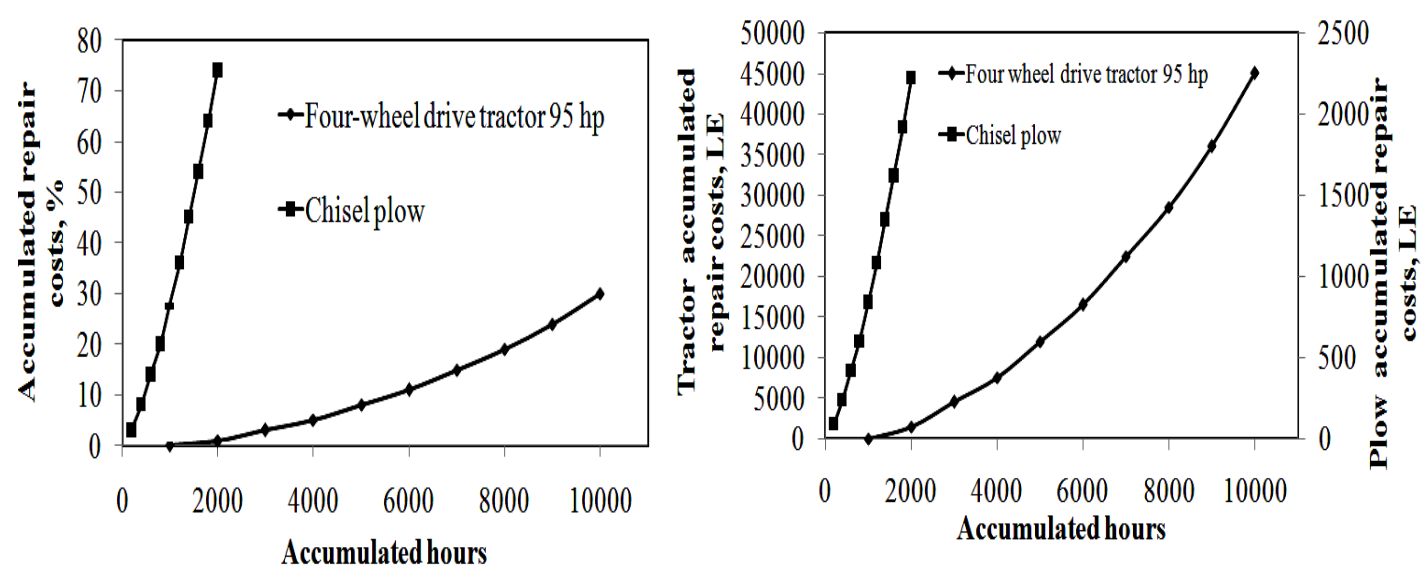

Fig. (8). The relationship between accumulated repair costs and accumulated hours.

\section{0- Accumulated repair costs}

Farm machinery cost is an important factor which reaches about 20 to $30 \%$ of total agriculture costs (Benchmark, 2009). Accurate information on machinery costs is therefore an essential input for farm managers. Machinery costs consist of several sub-cost items such as depreciation, interest rate, insurance, housing, fuel costs, repair and maintenance costs. The repair and maintenance cost is the most important factor to decide if the machine economically work or not. The relationship between accumulated repair costs and accumulated hours for the above mention tractor and chisel plow are shown in Fig. (8). It was observed that increasing accumulated hours from 200 to 2000 hours for chisel plow and from 1000 to 10000 hours for $95 \mathrm{hp}$ tractor resulted in increasing accumulated repair costs to 74 and $30 \%$ of the purchase price respectively (ASAE, 2000). It is very important to calculate accumulated repair costs for all machines at the farm machinery station to make a decision about repair the old machine or to buy new one.

\section{The situation of governmental farm machinery stations in Egypt}

The relationships between tractor numbers and years at the private and governmental sectors are shown in Fig.(9). It was observed a significant increase in the number of tractors in the private sector compared to the governmental sector in the same time period, which due to many problems that facing the governmental farm machinery stations as follow:

1- Increasing prices of fuel, lubrication and spare parts. 
2- There is no accurate information in the station about machine tracks in the field, machine life time, total labor hours, fuel consumption rates, accumulated repair costs, machine salvage value and the total area that have been done by the machine.

3- The unknown field specification such as (weather forecasts, field size, shape, topography, row length and row end turning space) which lead to decrease machine efficiency in the field and increase the actual time consumption.

4- Sometimes the drivers steal fuel or work in another farm without inform their mangers

5- There is no training courses to increase driver skills for use high technology machines

6- There is no plan to replace old machines

7- Use bad management system for farm machinery stations All these factors lead to decrease the performance of farm machinery stations and increase operating costs.

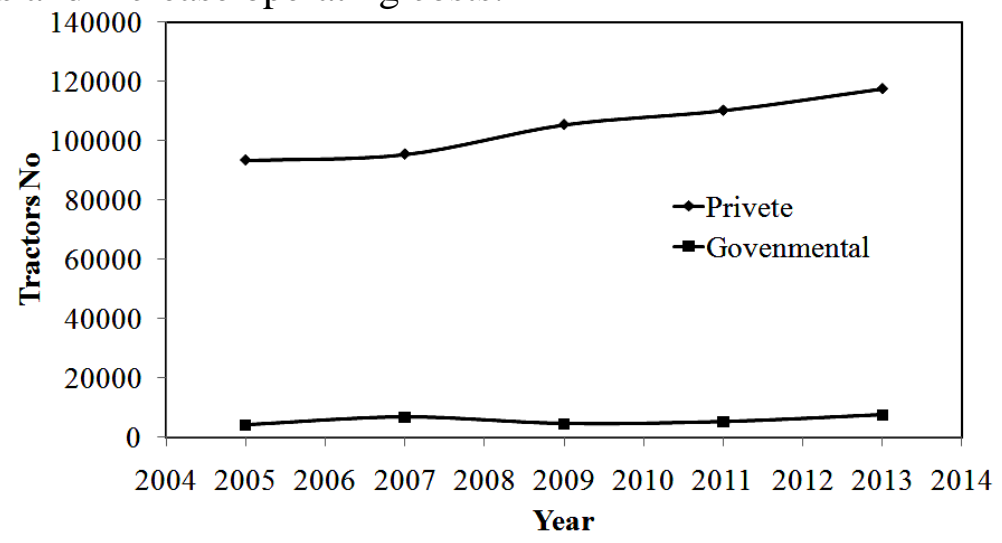

Fig. (9). Evolution of tractors numbers in the private and governmental sectors (CAPMAS, 2014).

\section{Advancement plan of governmental farm machinery stations}

1- Use GPS tracking system and Google Maps to determine machine tracks in the field, field size, shape, topography, row length and row end turning space which contribute on decrease actual time consumption.

2- Use renewable energy like biodiesel, biogas and solar energy to decrease fuel cost and environmental pollution. 
3- Organize training courses to increase driver skills for use high technology machines.

4- Use GPS tracking system prevents fuel stealing or working in another farm without inform manger

5- Create a database for all farm machinery in the station to record all agriculture processes in the field, which includes machine type, machine age, total labor hours, total completed area, machine speed, working depth, soil type, field shape, salvage value, accumulated repair costs and fuel consumption rate. The database can be used to predict the performance of the machine in the field at different conditions in the future.

\section{6- Make time plan to replace old machines}

7- Improve the management system for the farm machinery station by:

\section{A- Before operating farm machinery in the field}

The farmer fills application form to rent the machine from the station. The application form contains machine type, tractor size, the average area of the farm, number of rental days and finally the place of the farm on the map by Google maps.

The employee of the station determines:

1- Weather forecast at this time

2- The area and the shape of the field from the map

3- The best movement direction for the machine in the field to decrease time losses

4- The time losses in the field, the theoretical field capacity and the theoretical time consumption.

5- The power requirement for the machine to choose suitable tractor size without being under or over powered. Using incorrect tractor size in the farm leads to fuel waste or early breakdown.

6- The average fuel consumption

7- The average rental cost for the tractor and machine

\section{B- While operating farm machinery in the field}

The employee of the station watches the movement of the machine on the field by GPS tracker, which recording the position, the direction, the time and the speed of the machine on the map. The employee informs machine driver about directions, rotation places in the field and errors in the field. 
The employee records the number of stops in the field and the malfunctions.

\section{C- After finishing agriculture process by farm machinery}

The employee of the station calculates the actual area and the actual time consumption for this process to estimate machine rental cost. Every machine in the station should have data file to calculate the total working hour and the total area have been done by the machine.

\section{8- Use computer program for technical service support}

The farm machinery maintenance program was designed to calculate the total accumulated working hours in order to determine check points maintenance every fifty hour as shown in Fig. (10).

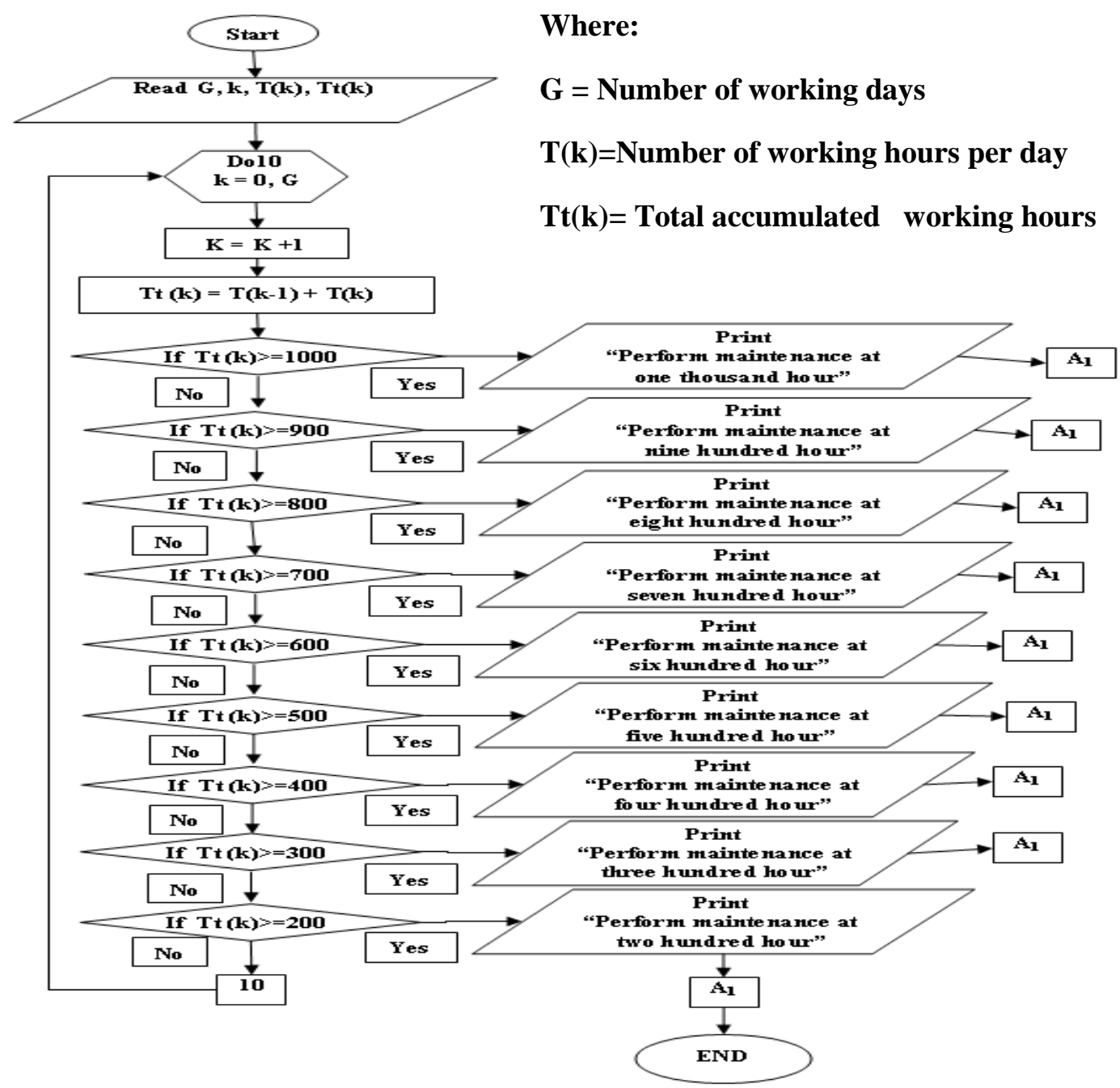

Fig. (10): Program flowchart to determine regular maintenance for farm machinery. 


\section{CONCLUSIONS}

Using GPS tracking system with Google Maps in operating and managing of farm machinery stations provides important information about field shape, area, dimensions and position of the machine on the map which leads to increase the performance of the machine in the field, decrease waste time and operate agriculture machinery in parallel lines.

It was observed that using GPS tracking system in operating farm machinery resulted in decreasing traveled distance by about $23.27 \%$ for the whole area and resulted in decreasing actual time consumption, energy consumption, fuel consumption and labor hours by about $7.14 \%$, while resulted in increasing field capacity and field efficiency by about $7.21 \%$ for the whole area. It was observed that increasing machine age resulted in decreasing salvage value from 100 to $20 \%$ through 20 year. It was observed that increasing accumulated hours from 200 to 2000 hours for chisel plow and from 1000 to 10000 hours for $95 \mathrm{hp}$ tractor resulted in increasing accumulated repair costs to 74 and $30 \%$ of the purchase price respectively

\section{REFERENCES}

American Society of Agricultural Engineers Yearbook. 2000. ASAE D230.3: Agricultural machinery management data. ASAE, St. Joseph, MI 49085.

Benchmark, 2009. Cash Crop Report 2009: Benchmarking Farming Systems Worldwide. Braunschweig: Agri Benchmark, von Thu" nen Institute.

Central Agency for Public Mobilization and statistics, 2014. Farm machinery statistics. 2014/18822.

Dahab, M.H. and Mohamed, O.E. (2006) A Computer Model for Selection of Farm Machinery. U. K. J. Agric. Sci. 14(2):167-181.

Ehsani, I., 2013. Increasing field efficiency of farm machinery using GPS. Uni of Florida, Institute of Food and Agric Sciences, Citrus Research and Education Center, 863-956-1151. 
Kutz, m., 2013. Handbook of farm, dairy and food machinery engineering. Elsevier, ISBN: 978-0-12-385881-8.

Michelin,. 2001. Optimum tire performance worksheet for tractors. North America, Inc, Farm Energy Innovation Program - Efficient Farm Vehicals.

Shamshiri, R. and W. Ishak, 2013. Exploring GPS Data for Operational Analysis of Farm Machinery. Res. J. Appl. Sci. Eng. Technol., 5(12): 3281-3286, 2013.

Williams, J., 2007. What size farm tractor do i need. Online Farm Energy Innovation Program - Efficient Farm Vehicals.

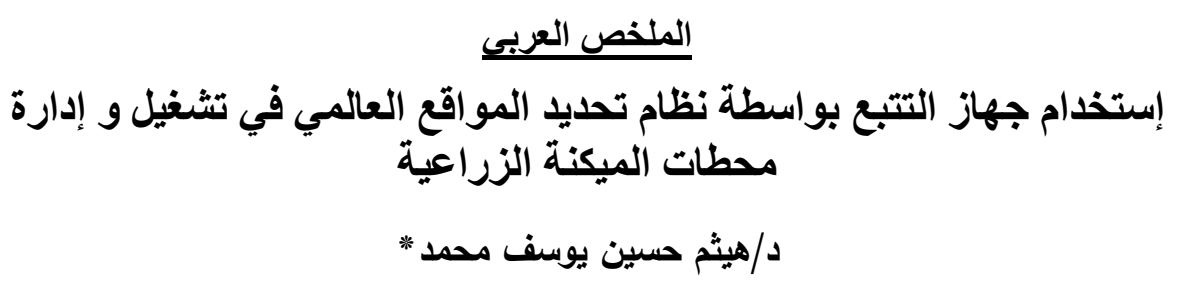

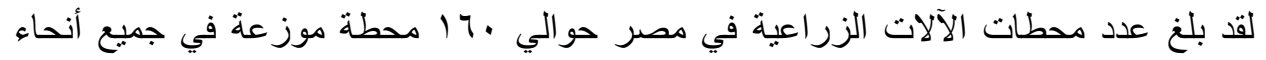

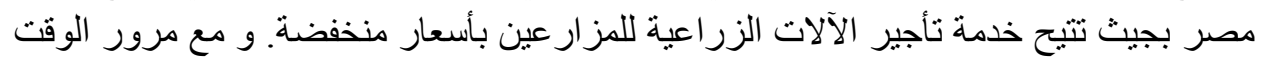

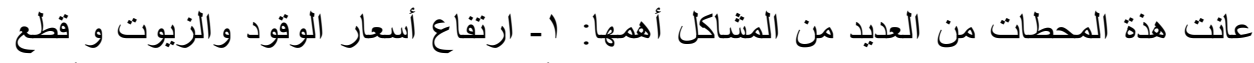

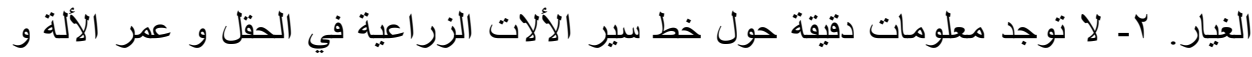

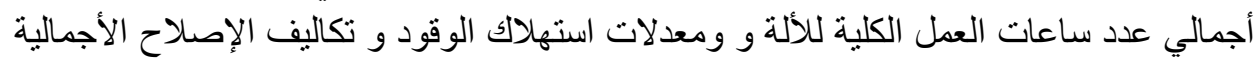

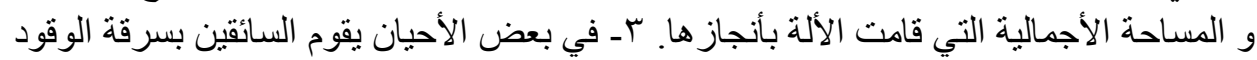

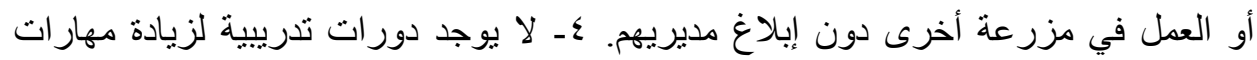

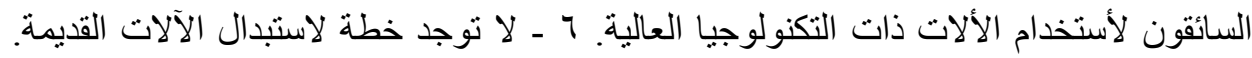

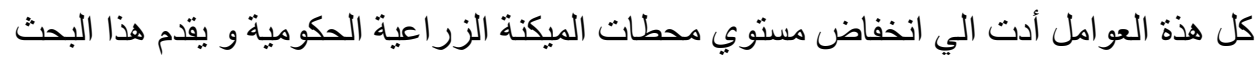

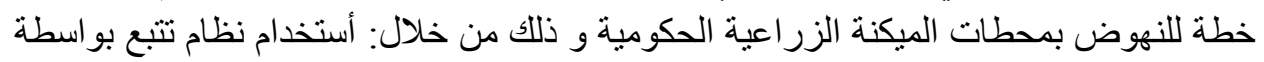

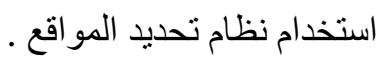

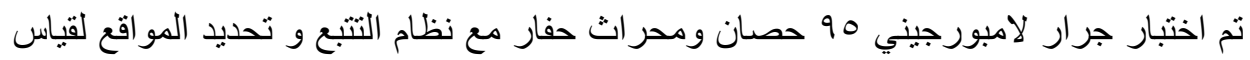

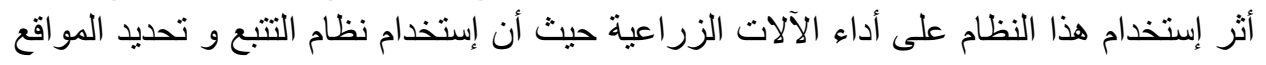

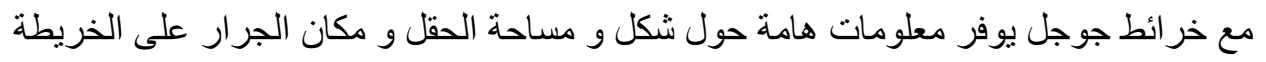
مما يؤدي إلى رفع كفاءة أداء الميكنة في الحقل.

مدرس الهنسة الزراعية - قسم الأراضي و الكيمياء الزراعية - كلية الزراعة ساباباثا - جامعة الأسكندرية 


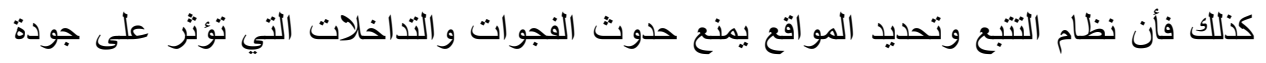

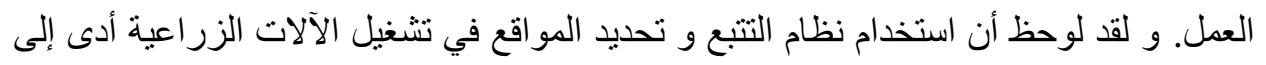

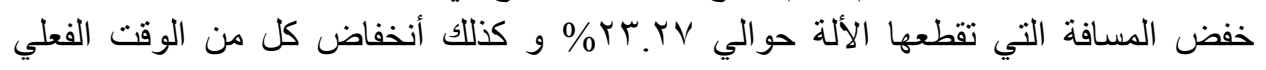

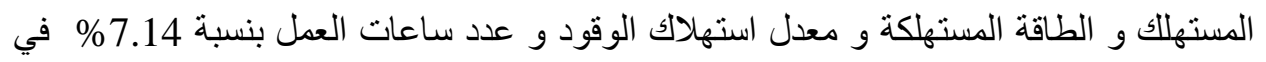

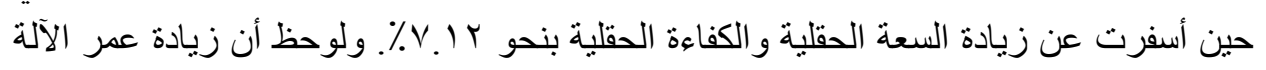

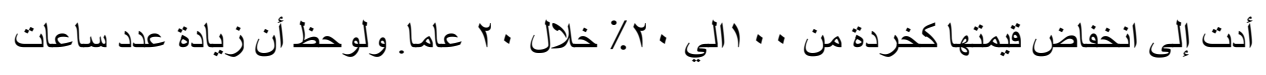

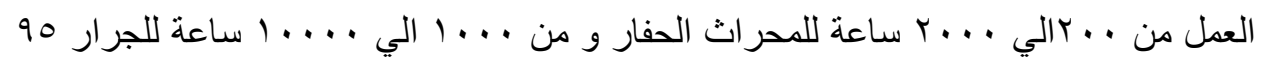

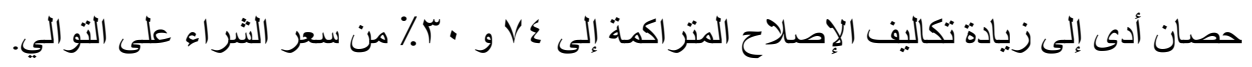

